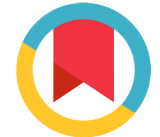

Check for updates
For correspondence:

amohamadii1361@gmail.com

Competing interests: The authors declare that no competing interests exist.

Received: 19 October 2017

Accepted: 07 November 2017

Published: 18 December 2017

Copyright The Author(s) 2017. This article is published with open access by BioMedPress

This article is distributed under the terms of the Creative Commons Attribution License (CC-BY 4.0) which permits any use, distribution, and reproduction in any medium, provided the original author(s) and the source are credited.

\section{Role of statin in increasing the risk of diabetes mellitus}

\section{Mahdi Mohammadian1,2,*, Hamid Salehiniya3, Jamshid Ovisey4, Fatemeh Allah Bakeshei5, Abdollah Mohammadian-Hafshejani6,7}

\section{Keywords}

Cardiovascular diseases, Diabetes mellitus, Statin

\section{Dear Editor-in-Chief}

Statin is known as one of the most commonly prescribed medicines in the United States (Bhattacharya et al., 2014). This drug is widely used with the aim to prevent risk of stroke and cardiovascular diseases as well as reduction of mortality from these diseases (Mohammadian et al., 2015; Ong et al., 2014). Several studies have recently paid attention to roles of Statins in increasing the risk of type 2 diabetes mellitus. Based on results of several clinical trials on prevention of cardiovascular diseases, Statin leads to an increased risk of type 2 diabetes mellitus (T2DM) (Crandall et al., 2017). This drug leads to an increase at 
fasting blood sugar, glycosylated hemoglobin (HbA1c) and blood sugar levels in recipients (Mohammadian et al., 2017; Ridker et al., 2012). According to a metaanalysis study by Sattar and et al on 13 clinical trials about Statins in 91140 participants, the treatment with Statin led to an increase of $9 \%$ in the risk of diabetes in a way that the Hazard Ratio (HR) of disease in subjects, who received Statin, was equal to 1.09 (confidence interval (Cl) of 95\%, (1.02-1.17)) compared with those who did not receive Statin (Sattar et al., 2010). According to a clinical trial by Jill P Crandall et al with the aim to investigate effects of three types of intervention (Metformin, Placebo or lifestyle change) in preventing or delaying type 2 diabetes mellitus in a group of people at high risk of diabetes, Statins led to an increased hazard of diabetes mellitus during a 10-year follow up period regardless of the group therapy, so that the HR of diabetes mellitus in subjects, who received Statin, was $1.36(\mathrm{Cl}$ of $95 \%,(1.17$ to 1.58$))$ compared to other people (Sattar et al., 2010). Therefore, based on results of clinical trials, despite the fact that Statin therapy leads to a slight increase in the risk of diabetes, this risk is low and physicians need to focus on the beneficial role of this drug in reducing cardiovascular diseases; hence, clinical recommendations for patients, who suffer from cardiovascular diseases, or people at high risk of these diseases should not be changed; and Statin therapy is still recommended to these patients.

\title{
Abbreviations
}

\author{
$\mathrm{Cl}$ :Confidence Interval \\ HbA1c: Glycosylated hemoglobin (A1c) \\ HR: Hazard Ratio \\ T2DM: Type 2 diabetes mellitus
}

\section{References}

Bhattacharya, R., Ajmera, M., Bhattacharjee, S., and Sambamoorthi, U. (2014). Use of antidepressants and statins and short-term risk of new-onset diabetes among high risk adults. Diabetes research and clinical practice 105, 251-260.

https://doi.org/10.1016/j.diabres.2014.04.016

Crandall, J.P., Mather, K., Rajpathak, S.N., Goldberg, R.B., Watson, K., Foo, S., Ratner, R., Barrett-Connor, E., and Temprosa, M. (2017). Statin use and risk of developing diabetes: results from the Diabetes Prevention Program. BMJ open diabetes research \& care 5, e000438.

https://doi.org/10.1136/bmjdrc-2017-000438 
Mohammadian, M., Hosseini, S., Sadeghi, M., Sarrafzadegan, N., Salehiniya, H., Roohafza, H., Khazaei, S., and Mohammadian-Hafshejani, A. (2015). Trends of 28 days case fatality rate after first acute myocardial infarction in Isfahan, Iran, from 2000 to 2009. ARYA atherosclerosis 11, 233-243.

Mohammadian, M., Salehiniya, H., Khazaei, S., and Mohammadian-Hafshejani, A. (2017). Intensification of Metformin treatment in diabetic patients with Insulin versus Sulfonylureas. Biomedical Research and Therapy 4, 1341-1343.

https://doi.org/10.15419/bmrat.v4i06.177

Ong, K.L., Waters, D.D., Messig, M., DeMicco, D.A., Rye, K.A., and Barter, P.J. (2014). Effect of change in body weight on incident diabetes mellitus in patients with stable coronary artery disease treated with atorvastatin (from the treating to new targets study). The American journal of cardiology 113, 1593-1598.

https://doi.org/10.1016/j.amjcard.2014.02.011

Ridker, P.M., Pradhan, A., MacFadyen, J.G., Libby, P., and Glynn, R.J. (2012). Cardiovascular benefits and diabetes risks of statin therapy in primary prevention: an analysis from the JUPITER trial. Lancet (London, England) 380, 565-571.

https://doi.org/10.1016/S0140-6736(12)61190-8

Sattar, N., Preiss, D., Murray, H.M., Welsh, P., Buckley, B.M., de Craen, A.J., Seshasai, S.R., McMurray, J.J., Freeman, D.J., Jukema, J.W., et al. (2010). Statins and risk of incident diabetes: a collaborative meta-analysis of randomised statin trials. Lancet (London, England) 375, 735-742.

https://doi.org/10.1016/S0140-6736(09)61965-6 